\title{
BMJ Open Relation between carotid stiffness, cognitive performance and brain connectivity in a healthy middle-aged population: an observational neurophysiological cohort study with magnetoencephalography
}

\author{
Dagmar Nieboer, ${ }^{1}$ Linda Douw, ${ }^{2,3}$ Bob W van Dijk, ${ }^{4,5}$ Martijn W Heymans, ${ }^{1,6}$ \\ Cornelis J Stam, ${ }^{4}$ Jos W R Twisk ${ }^{6}$
}

To cite: Nieboer D, Douw L, van Dijk BW, et al. Relation between carotid stiffness, cognitive performance and brain connectivity in a healthy middle-aged population: an observational

neurophysiological cohort study with

magnetoencephalography. BMJ Open 2016;6:e013441. doi:10.1136/bmjopen-2016013441

- Prepublication history for this paper is available online To view these files please visit the journal online (http://dx.doi.org/10.1136/ bmjopen-2016-013441).

Received 12 July 2016 Revised 1 November 2016 Accepted 3 November 2016

CrossMark

For numbered affiliations see end of article.

Correspondence to

Dagmar Nieboer;

d.nieboer@vu.nl

\section{ABSTRACT}

Objective: Impaired blood flow of the carotid artery can result in cognitive impairment, but how these vascular impairments lead to global cognitive disturbances is largely unknown. Problems in functional connectivity between brain areas may be responsible for these widespread effects. Therefore, the aim of this study was to examine the association between carotid stiffness, functional connectivity and cognitive performance in relatively young and healthy adults before clinical vascular pathology occurs.

Design: The Amsterdam Growth and Health Longitudinal Study: an observational study.

Setting: Participants were included by attending 1 of the 2 selected secondary schools in The Netherlands.

Participants: Men $(n=110)$ and women $(n=120)$ aged 41-44 years $(42 \pm 0.7)$.

Primary and secondary outcome measures: Data were obtained with regard to local carotid stiffness captured measured with the Young's elastic modulus (YEM). All participants underwent a commonly used Dutch intelligence test and resting-state eyes-closed magnetoencephalography (MEG). Five artefact-free epochs were analysed. The phase lag index (PLI) was used as a measure of functional connectivity between all sensors and was assessed in six frequency bands $(\delta-\gamma)$.

Results: Carotid stiffness was significantly associated with increased functional connectivity in the $\alpha 2$ band in men ( $\beta: 0.287 ; p=0.008)$. The same results were found for women in the $\beta$ band ( $\beta: 0.216 ; p=0.040$ ). Furthermore, carotid stiffness was associated with superior cognitive function in men ( $\beta: 0.238 ; p=0.007)$. In addition, there was neither a significant association nor a consistent pattern between cognitive function and functional connectivity.

Conclusions: The increased connectivity might be a maladaptive phenomenon caused by disinhibition of neurons which may explain the direction of the results. This study suggests that detection of increased (local)

\section{Strengths and limitations of this study}

- Magnetoencephalography recording has not been performed on such a large scale in apparently healthy individuals; therefore, this study gives a good indication of the relation between carotid stiffness and functional connectivity in a healthy population.

- Our sample size allows us to stratify the results by gender, which is an important advantage since it is known that the brain organisation differs between men and women.

- Since MRI is not available for the participants within the Amsterdam Growth and Health Longitudinal Study, we were not able to apply the source-space technique in order to provide a detailed topographic view of the brain.

- The population is homogeneous concerning age, which indicates that secular trends cannot be investigated within this cohort.

- A limitation of this study is the fact that we are not able to support a temporal or causal relation between arterial stiffness, functional connectivity and intelligent quotient.

carotid stiffness may be promising to identify a disturbance in the organisation of the functional brain network, even before clinical vascular pathology occurs.

\section{INTRODUCTION}

Arterial stiffness, which describes the rigidity of the arterial walls, is increasingly seen as a useful diagnostic tool in daily medical practice to predict cardiovascular events in patients at risk. ${ }^{12}$ Research has shown that vessel wall stiffness leads to increased cardiovascular risk, and 
also that there is also a close relationship between vessel wall stiffness and cognitive functioning, that is, higher vessel wall stiffness is related to cognitive decline. ${ }^{3}$ This relationship persists in the elderly, those with a disease and even in middle-aged individuals suffering from impaired brain function. ${ }^{4-11}$ The pathophysiological mechanism behind arterial stiffness and cognitive function might be explained by the fact that higher levels of pulsatile pressure might cause structural changes and a dysfunction of the microcirculation. ${ }^{12}$ This may result in microvascular damage and impaired microvascular function, with impaired cognition or loss of cognitive function as a result. ${ }^{12}{ }^{13} \mathrm{~A}$ recent longitudinal study showed an association between increased arterial stiffness, subclinical vascular brain injury and greater neurocognitive decline in healthy older adults. ${ }^{14}$ However, little is known about this relationship in the preceding period, namely in healthy middle-aged adults.

Cognitive functioning is considered to be dependent on interactions between different brain regions, rather than on a single brain region or structure. ${ }^{15}$ Therefore, viewing the brain as a complex network has become a widely applied framework in the field of neuroscience in recent years. ${ }^{16} 17$ One approach to map this complex network is by measuring the magnetic fields of the brain with magnetoencephalography (MEG). MEG reflects the brain's activity by measuring fluctuations in magnetic fields at the scalp with millisecond temporal resolution. This technique allows us to estimate functional connectivity, which refers to the statistical interdependencies between time series of neural activity recorded from different brain regions that reflect functional interactions and information exchange between the regions. ${ }^{18} \mathrm{~A}$ powerful method that can be used to detect this synchronous neuronal activity is the phase lag index (PLI). ${ }^{19}$

Since functional connectivity may partly explain cognitive function, ${ }^{20}$ significant changes in functional connectivity might account for cognitive deterioration in neurological disease ${ }^{21}$ and vessel wall stiffness is related to cognitive decline, ${ }^{3}$ it is important to examine the relation between carotid stiffness, functional connectivity and cognition. Therefore, the objective of this explorative study is to examine the cross-sectional associations between carotid stiffness, functional connectivity and cognitive performance in relatively young and healthy adults before clinical vascular pathology occurs. We hypothesise that higher carotid stiffness may lead to a disturbance in the functional connectivity of the brain and that this disturbance may be associated with poorer cognitive performance.

\section{METHODS}

\section{Participants and study design}

All participants participated in the Amsterdam Growth Health and Longitudinal Study (AGHLS; approved by the medical ethical committee of the VU University, Amsterdam, The Netherlands; all participants gave written consent at each subsequent measurement occasion). The AGHLS is a population-based observational longitudinal study, started in 1976, that aims to describe the natural development of growth, health and lifestyle during adolescence and adulthood. The rationale and design of the AGHLS have been described elsewhere in detail. $^{22-24}$ Of all participants invited to the measurement rounds in 2000 and 2006, 230 from the original cohort $(\mathrm{n}=698)$ attended both measurement rounds and had complete data.

\section{Carotid stiffness}

Young's elastic modulus (YEM) is an estimate of the intrinsic elastic properties of the vessel wall and represents the stiffness of the arterial wall material at operating pressure. This local estimate of arterial stiffness was obtained through an ultrasound imaging device connected to a computer equipped with vessel wall movement detector software (Wall Track System 2, Pie Medical, Maastricht, the Netherlands). In both measurement rounds, an identical protocol was followed. This protocol is described in detail elsewhere. ${ }^{25} 26$ During the measurement, the arterial diameter (D), intima-media-thickness (IMT) and distension $(\Delta \mathrm{D})$ were quantified by ultrasonography, determined according to the Van Bortel calibration method of distension waveforms. ${ }^{27}$ YEM was calculated as follows: YEM=D/ $(\mathrm{IMT} \times \mathrm{DC})$ in $10^{3} \mathrm{kPa}$. In order to obtain a more stable indicator of arterial stiffness, the average value of YEM was taken from the two subsequent measurement rounds.

\section{Cognitive performance}

At the mean age 42 , all participants underwent a validated short version of the Groningen Intelligence Test (GIT),${ }^{28}$ which is a Dutch intelligence test that is commonly used in the Netherlands for purposes comparable to the Wechsler Adult Intelligence Scale (WAIS) to determine general intelligence, expressed in Intelligent Quotient (IQ). ${ }^{29}$ Higher scores on the cognitive test indicate superior performance. Luteijn and Van der Ploeg reported Cronbach's $\alpha$ of the total GIT to be 0.97 and a correlation with the shortened version of 0.94 with the complete test. ${ }^{28}$ The shortened version of the GIT was used as a measure of general ability and consisted of the subtest 'spatial jigsaw puzzles', 'arithmetic' and 'word matrices' with an average internal consistency of $0.92 .{ }^{30}$ It took $\sim 45 \mathrm{~min}$ to complete the test.

\section{MEG acquisition}

MEG recordings were obtained at the mean age 42, using a 151-channel whole-head MEG system (CTF Systems Inc., Port Coquitlam, British Columbia, Canada), while participants were seated inside a magnetically shielded room. During the measurement, magnetic fields were obtained during a 5 min no-task, eyes-closed condition. Head movements of at most $1.5 \mathrm{~cm}$ during acquisition were allowed. At the end of the measurements, five artefact-free epochs of 4096 
samples (6.554s) were selected by one of the authors (BWvD). ${ }^{31}$ Those epochs were selected that did not contain system-related artefacts (SQUID jumps, noisy, saturated channels), physiological artefacts (eye movement, eye blinks, muscle artefacts) or excessive environmental noise. ${ }^{32}$ All data analyses were performed using BrainWave software (CJS, V.0.9.58 available from http:// home.kpn.nl/stam7883/brainwave.html). The obtained epochs were band-pass filtered into the six frequency bands which were used separately in further analyses: $\delta$ $(0.5-4 \mathrm{~Hz}), \theta(4-8 \mathrm{~Hz}), \alpha 1(8-10 \mathrm{~Hz}), \alpha 2(10-13 \mathrm{~Hz}), \beta$ $(13-30 \mathrm{~Hz})$ and $\gamma(30-45 \mathrm{~Hz})$. Sensor values for connectivity were averaged for five regions: frontal, central, parietal, occipital and temporal.

\section{Phase lag index}

As a measure of functional connectivity, the PLI was calculated. The PLI calculates the asymmetry of the distribution of phase differences between two time series and ranges between 0 and 1 . The asymmetry of the distribution of phase differences of two signals can be obtained from a time series of phase differences $\Delta \Phi\left(\mathrm{t}_{\mathrm{k}}\right), \mathrm{k}=1 \ldots N$ samples:

$$
\mathrm{PLI}=\left|<\operatorname{sign}\left[\sin \left(\Delta \varphi\left(\mathrm{t}_{\mathrm{k}}\right)\right)\right]>\right|
$$

The phase difference, $\Delta \phi$, is defined in the interval $[-2 \pi$, $2 \pi]$; the absolute value of the average sign of the phase difference mapped back to $[-\pi,+\pi]$ and will be close to 1 if there is a stable phase difference unequal to $\mathrm{k} \pi$. A PLI of 0 (modulo pi) implies no coupling or coupling with a phase difference of $0^{\circ}$ or $\pm 180^{\circ}$. The presence of a consistent, non-zero phase lag between two time series reflects true interaction instead of volume conduction or common sources. By calculating the PLI, it is more likely to find true interactions instead of volume conduction. ${ }^{19}$ Regional and overall (whole-brain) PLI were computed by averaging all values for the different brain regions.

\section{Covariates}

To adjust for known confounding factors, biological variables as well as lifestyle variables have been taken into account. In both examinations, we measured participants' height, mean arterial pressure, body fat percentage and level of triglyceride to HDL-C (TG/HDL-C) ratio and we obtained information on participants' smoking status and antihypertensive medication use. Body fat percentage was measured with a DEXA scan, and levels of triglyceride and HDL-cholesterol were measured by enzymatic techniques (Roche Diagnostics $\mathrm{GmbH}$, Mannheim, Germany). Smoking status was examined with a validated questionnaire. ${ }^{33}$ Furthermore, antihypertensive medication was examined with a questionnaire and was presented as a dichotomous variable (yes/no).

\section{Statistical analysis}

The association between cognition and functional connectivity was assessed with linear regression analysis for all six frequency bands separately and stratified by gender and was adjusted for mean arterial pressure, height, body fat percentage, smoking, TG/HDL-C and antihypertensive medication use. The average value of YEM was used in all analyses and was stratified by gender and adjusted for mean arterial pressure and height. Results of all analyses were expressed as standardised regression coefficients $(\beta)$, to enable comparison of the strengths of the association. All statistical analyses were performed with SPSS statistical software (IBM SPSS, statistics, V.21.0), and a two-sided $p$ value of $<0.05$ was considered to be statistically significant.

\section{RESULTS}

\section{Participant characteristics}

Table 1 summarises the characteristics of all participants included in the current analysis separately for men $(n=110)$ and women $(n=120)$. In both genders, higher values of YEM, increased stiffness, were found during the latter measurement round of 2006.

\section{Carotid stiffness and cognitive performance}

Tables 2 and 3 show the results of the association between average carotid stiffness and cognitive performance. For men, YEM was associated with superior cognitive function in men (table 2), while in women no association was identified (table 3 ).

\section{Carotid stiffness and functional connectivity}

Tables 4 and 5 show the results of the analyses correlating average carotid stiffness with functional connectivity. For YEM, which reflects the intrinsic elastic properties of the vessel wall, for almost all frequency bands, a positive association with PLI was found, suggesting a consistent pattern. Regarding significance, in the $\alpha 2$ band, for men, a significant positive association was found (table 4), while in the $\beta$ band for women, a significant positive association was found (table 5).

The association between PLI and YEM is illustrated in more detail in figure 1. At the sensor level, $p$ values for the association of PLI with YEM were not significant in men (figure 1A), while in women, a significant and global pattern could be noticed (figure 1B).

\section{Cognitive performance and functional connectivity}

There was neither a significant association nor a consistent pattern between cognition and PLI (tables 6 and 7).

\section{Additional analysis}

Some additional analyses were performed to examine whether the mean value of the carotid stiffness as an independent variable may cause an overestimation or underestimation of the association between carotid stiffness and functional connectivity. The relationship was examined with vessel wall stiffness data, expressed as YEM, in 2000 and 2006 separately. Using data from 2000 did not change the relation between carotid stiffness and functional 
Table 1 General characteristics of the study population

\begin{tabular}{|c|c|c|c|c|c|c|}
\hline & \multicolumn{3}{|l|}{ Men $(n=110)$} & \multicolumn{3}{|c|}{ Women $(n=120)$} \\
\hline & 2000 & 2006 & $\overline{\mathbf{x}} 2000-2006$ & 2000 & 2006 & $\overline{\mathbf{x}}$ 2000-2006 \\
\hline Age (years) & $35.96 \pm 0.69$ & $42.06 \pm 0.73$ & & $36.08 \pm 0.73$ & $42.09 \pm 0.71$ & \\
\hline Systolic blood pressure (mm Hg) & $121.02 \pm 10.39$ & $123.02 \pm 13.95$ & $122.02 \pm 10.88$ & $112.13 \pm 10.95$ & $111.52 \pm 12.89$ & $111.83 \pm 10.78$ \\
\hline Diastolic blood pressure (mm Hg) & $66.67 \pm 6.74$ & $73.40 \pm 7.79$ & $70.04 \pm 6.39$ & $63.32 \pm 7.28$ & $68.29 \pm 8.04$ & $65.81 \pm 6.97$ \\
\hline Pulse pressure $(\mathrm{mm} \mathrm{Hg})$ & $54.35 \pm 5.81$ & $49.63 \pm 9.59$ & $51.99 \pm 6.84$ & $48.81 \pm 5.90$ & $43.23 \pm 7.80$ & $46.02 \pm 6.03$ \\
\hline Mean arterial pressure $(\mathrm{mm} \mathrm{Hg})$ & $84.79 \pm 7.66$ & $89.94 \pm 9.22$ & $87.37 \pm 7.51$ & $79.59 \pm 8.22$ & $82.70 \pm 9.22$ & $81.15 \pm 7.94$ \\
\hline Height $(\mathrm{cm})$ & $184 \pm 6.96$ & $184 \pm 6.68$ & $184 \pm 6.68$ & $171 \pm 6.55$ & $171 \pm 6.41$ & $171 \pm 6.49$ \\
\hline Distensibility coefficient $\left(10^{-3} / \mathrm{kPa}\right)$ & $25.98 \pm 5.22$ & $24.80 \pm 7.38$ & $25.40 \pm 5.42$ & $26.67 \pm 6.15$ & $26.09 \pm 7.13$ & $26.38 \pm 5.68$ \\
\hline Compliance coefficient $\left(\mathrm{mm}^{2} / \mathrm{kPa}\right)$ & $1.05 \pm 0.26$ & $1.06 \pm 0.33$ & $1.05 \pm 0.26$ & $0.91 \pm 0.23$ & $0.95 \pm 0.28$ & $0.93 \pm 0.22$ \\
\hline Triglyceride (mmol/L) & $1.58 \pm 1.08^{*}$ & $1.40 \pm 1.03 \dagger$ & $1.48 \pm 0.96 \dagger$ & $0.98 \pm 0.43$ & $0.96 \pm 0.46 \ddagger$ & $0.97 \pm 0.39 \ddagger$ \\
\hline HDL-C (mmol/L) & $1.22 \pm 0.27^{*}$ & $1.51 \pm 0.35$ & $1.37 \pm 0.29 \dagger$ & $1.57 \pm 0.31$ & $1.92 \pm 0.35 \ddagger$ & $1.75 \pm 0.33 \ddagger$ \\
\hline Smoking & & $20(18.2 \%)$ & & & $15(12.5 \%)$ & \\
\hline Body fat percentage & $20.1 \pm 3.3$ & $20.6 \pm 5.4$ & $20.3 \pm 3.9$ & $29.2 \pm 4.3$ & $33.9 \pm 7.9 \S$ & $31.5 \pm 5.7 \S$ \\
\hline Hypertension treatment $(\mathrm{n}, \%)$ & & $3(2.7)$ & & & $4(3.3)$ & \\
\hline Young's elastic modulus $\left(10^{3} \mathrm{kPa}\right)$ & $0.48 \pm 0.12$ & $0.51 \pm 0.16$ & $0.49 \pm 0.12$ & $0.43 \pm 0.12$ & $0.45 \pm 0.16$ & $0.44 \pm 0.12$ \\
\hline IQ score & & $109 \pm 13$ & & & $106 \pm 14$ & \\
\hline PLI $\delta$ & & $0.155 \pm 0.012$ & & & $0.159 \pm 0.015$ & \\
\hline PLI $\theta$ & & $0.138 \pm 0.012$ & & & $0.137 \pm 0.012$ & \\
\hline PLI $\alpha 1$ & & $0.203 \pm 0.026$ & & & $0.207 \pm 0.289$ & \\
\hline PLI $\alpha 2$ & & $0.178 \pm 0.028$ & & & $0.175 \pm 0.026$ & \\
\hline PLI $\beta$ & & $0.075 \pm 0.005$ & & & $0.076 \pm 0.009$ & \\
\hline PLI $\gamma$ & & $0.070 \pm 0.003$ & & & $0.071 \pm 0.003$ & \\
\hline \multicolumn{7}{|c|}{$\begin{array}{l}\text { Values are expressed as mean } \pm \text { SD or percentages. } \\
\bar{x} 2000-2006 \text { refers to the average value of the measurements in } 2000 \text { and } 2006 . \\
\text { *Refers to } 108 \text { men. } \\
\text { †Refers to } 107 \text { men. } \\
\text { †Refers to } 116 \text { women. } \\
\text { §Refers to } 118 \text { women. } \\
\text { PLI, phase lag index. }\end{array}$} \\
\hline
\end{tabular}

Table 2 Association between carotid stiffness and cognitive performance (IQ) in men

\begin{tabular}{|c|c|c|c|c|}
\hline \multirow[b]{2}{*}{ Men } & \multicolumn{4}{|c|}{ Carotid YEM† } \\
\hline & Model & $\boldsymbol{\beta}$ & p Value & $95 \% \mathrm{Cl}$ \\
\hline \multicolumn{5}{|c|}{ Dependent variable } \\
\hline \multirow[t]{4}{*}{ IQ } & 1 & 0.222 & 0.020 & 0.036 to $0.408^{*}$ \\
\hline & 2 & 0.288 & 0.008 & 0.077 to $0.499^{* *}$ \\
\hline & 3 & 0.297 & 0.006 & 0.085 to $0.509^{\star \star}$ \\
\hline & $4 \ddagger$ & 0.238 & 0.007 & 0.067 to $0.410^{*}$ \\
\hline
\end{tabular}

Note. Standardised regression coefficients $(\beta)$ as obtained from multiple linear regression analyses.

Mode 1; crude model.

Model 2; adjusted for mean arterial pressure (MAP).

Model 3; model 2, additionally adjusted for height.

Model 4; model 3, additionally adjusted for TG/HDL-C, smoking,

body fat percentage, hypertension treatment.

${ }^{*} \mathrm{p}<0.05 ;{ }^{* *} \mathrm{p}<0.01$

tData refer to 110 men

†Refers to 107 men.

connectivity, and nor did the use of the YEM data from the measurement round in 2006 (data not shown).

\section{DISCUSSION}

The present study was undertaken to evaluate the association between local arterial stiffness of the carotid artery,
Table 3 Association between carotid stiffness and cognitive performance $(\mathrm{IQ})$ in women

\begin{tabular}{lclll}
\hline \multirow{5}{*}{ Women } & \multicolumn{4}{l}{ Carotid YEM† } \\
\cline { 2 - 5 } Mependent variable & $\boldsymbol{\beta}$ & $\mathbf{p}$ Value & $\mathbf{9 5 \%} \mathbf{C l}$ \\
$\mathrm{IQ}$ & 1 & 0.009 & 0.925 & -0.174 to 0.191 \\
& 2 & 0.016 & 0.881 & -0.192 to 0.223 \\
& 3 & 0.038 & 0.717 & -0.171 to 0.248 \\
& $4 \ddagger$ & 0.036 & 0.675 & -0.134 to 0.206 \\
\hline
\end{tabular}

Standardised regression coefficients $(\beta)$ as obtained from multiple linear regression analyses.

Mode 1; crude model.

Model 2; adjusted for mean arterial pressure (MAP).

Model 3; model 2, additionally adjusted for height.

Model 4; model 3, additionally adjusted for TG/HDL-C, smoking,

body fat percentage, hypertension treatment.

†Data refer to 120 women.

$\ddagger$ Refers to 116 women.

the brain's functional connectivity and cognitive performance in healthy middle-aged participants. The main findings of this study are threefold. First, increased local arterial stiffness of the carotid artery, expressed in terms of YEM, was significantly positively related to cognitive performance in men. The second finding is that greater local arterial stiffness was related to higher functional 
Table 4 Association between carotid stiffness and functional connectivity in men

\begin{tabular}{|c|c|c|c|c|}
\hline \multirow[b]{2}{*}{ Men } & \multicolumn{4}{|c|}{ Carotid YEM† } \\
\hline & Model & $\boldsymbol{\beta}$ & p Value & $95 \% \mathrm{Cl}$ \\
\hline \multicolumn{5}{|c|}{ Dependent variables } \\
\hline \multirow[t]{3}{*}{ PLI $\delta$} & 1 & -0.106 & 0.268 & -0.296 to 0.083 \\
\hline & 2 & -0.065 & 0.549 & -0.282 to 0.151 \\
\hline & 3 & -0.084 & 0.437 & -0.299 to 0.130 \\
\hline \multirow[t]{3}{*}{ PLI $\theta$} & 1 & 0.113 & 0.238 & -0.076 to 0.303 \\
\hline & 2 & 0.136 & 0.217 & -0.081 to 0.352 \\
\hline & 3 & 0.134 & 0.227 & -0.085 to 0.352 \\
\hline \multirow[t]{3}{*}{ PLI $\alpha 1$} & 1 & 0.106 & 0.271 & -0.084 to 0.295 \\
\hline & 2 & 0.101 & 0.357 & -0.116 to 0.318 \\
\hline & 3 & 0.109 & 0.325 & -0.110 to 0.327 \\
\hline \multirow[t]{3}{*}{ PLI $\alpha 2$} & 1 & 0.293 & 0.002 & 0.110 to $0.475^{\star *}$ \\
\hline & 2 & 0.285 & 0.008 & 0.076 to $0.493^{\star *}$ \\
\hline & 3 & 0.287 & 0.008 & 0.076 to $0.497^{* *}$ \\
\hline \multirow[t]{3}{*}{ PLI $\beta$} & 1 & 0.086 & 0.370 & -0.104 to 0.267 \\
\hline & 2 & 0.088 & 0.423 & -0.129 to 0.305 \\
\hline & 3 & 0.094 & 0.398 & -0.125 to 0.313 \\
\hline \multirow[t]{3}{*}{ PLI $\gamma$} & 1 & 0.049 & 0.609 & -0.141 to 0.240 \\
\hline & 2 & 0.035 & 0.752 & -0.183 to 0.252 \\
\hline & 3 & 0.038 & 0.730 & -0.181 to 0.258 \\
\hline
\end{tabular}

Note. Standardised regression coefficients ( $\beta$ ) as obtained from multiple linear regression analyses.

${ }^{* *} p<0.01$.

†Data refer to 110 men. Model 1: crude model; Model 2: adjusted for mean arterial pressure (MAP); Model 3: model 2, additionally adjusted for height. connectivity in men and women. Finally, no association was observed between functional connectivity and cognitive performance in men and women.

This study shows that greater arterial stiffness is positively correlated with superior cognitive performance in men. In contrast to our study, a recent systematic review reported fairly consistent evidence that greater arterial stiffness is related to a decrease in cognitive performance. ${ }^{3}$ However, studies that examined the cross-sectional association between arterial stiffness and global cognitive function via the Mini-mental Status Examination (MMSE) were inconsistent as opposed to studies that measured cognitive function with an array of neuropsychological tests. ${ }^{3}$ Furthermore, decreased executive function and lower memory scores in relatively healthy community-based participants were associated with arterial stiffness. ${ }^{6} 13{ }^{34}$ Moreover, a longitudinal modelling study revealed an overall inverted-U shape (quadratic) trajectory across basic and everyday domains of cognition in a healthy cohort with a mean age of 74 years. ${ }^{35}$ This finding might explain the counterintuitive positive association between vessel wall stiffness and cognition that we report, since our study population is younger and their cognition is not buffered against decline yet. It still remains unclear at which point in time the alteration of the carotid artery will attribute to cognitive decline. In addition, a recent study found that aortic stiffness was associated with poorer cognitive function in those aged $45-65$ years, but not in those aged $30-45$ years. ${ }^{36}$
Table 5 Association between carotid stiffness and functional connectivity in women

\begin{tabular}{|c|c|c|c|c|}
\hline \multirow[b]{2}{*}{ Women } & \multicolumn{4}{|c|}{ Carotid YEM† } \\
\hline & Model & $\boldsymbol{\beta}$ & p Value & $95 \% \mathrm{Cl}$ \\
\hline \multicolumn{5}{|c|}{ Dependent variables } \\
\hline \multirow[t]{3}{*}{ PLI $\delta$} & 1 & 0.003 & 0.978 & -0.180 to 0.185 \\
\hline & 2 & 0.044 & 0.673 & -0.163 to 0.251 \\
\hline & 3 & 0.044 & 0.677 & -0.166 to 0.255 \\
\hline \multirow[t]{3}{*}{ PLI $\theta$} & 1 & 0.102 & 0.267 & -0.079 to 0.284 \\
\hline & 2 & 0.064 & 0.541 & -0.142 to 0.270 \\
\hline & 3 & 0.062 & 0.560 & -0.148 to 0.271 \\
\hline \multirow[t]{3}{*}{ PLI $\alpha 1$} & 1 & -0.042 & 0.645 & -0.225 to 0.140 \\
\hline & 2 & -0.047 & 0.656 & -0.254 to 0.161 \\
\hline & 3 & -0.030 & 0.781 & -0.240 to 0.181 \\
\hline \multirow[t]{3}{*}{ PLI $\alpha 2$} & 1 & 0.191 & 0.037 & 0.012 to 0.369 \\
\hline & 2 & 0.175 & 0.092 & -0.029 to 0.378 \\
\hline & 3 & 0.158 & 0.127 & -0.045 to 0.361 \\
\hline \multirow[t]{3}{*}{ PLI $\beta$} & 1 & 0.206 & 0.024 & 0.027 to 0.384 \\
\hline & 2 & 0.212 & 0.041 & 0.009 to 0.415 \\
\hline & 3 & 0.216 & 0.040 & 0.011 to 0.421 \\
\hline \multirow[t]{3}{*}{ PLI $\gamma$} & 1 & 0.113 & 0.217 & -0.068 to 0.295 \\
\hline & 2 & 0.082 & 0.791 & -0.124 to 0.295 \\
\hline & 3 & 0.092 & 0.381 & -0.116 to 0.300 \\
\hline
\end{tabular}

Note. Standardised regression coefficients $(\beta)$ as obtained from multiple linear regression analyses.

${ }^{*} \mathrm{p}<0.05$

†Data refer to 120 women. Model 1: crude model; Model 2: adjusted for mean arterial pressure (MAP); Model 3: model 2, additionally adjusted for height.

Previous research indicates that greater arterial stiffness is associated with a higher risk of developing cardiovascular diseases in those who are already at risk for cardiovascular problems. ${ }^{37}$ Furthermore, lower arterial stiffness is associated with higher levels of cardiorespiratory fitness (ie, $\mathrm{VO}_{2}$ max), which implies that a healthy lifestyle reduces cardiovascular disease. ${ }^{38}$ Here, we show a positive association between arterial stiffness and both functional connectivity and cognitive functioning in healthy, young participants. A recent paper based on the same cohort suggests that cognitive functioning and physical fitness (ie, $\mathrm{VO}_{2} \max$ ) are correlated to network organisation. ${ }^{39}$ Together with our current results, it seems that a healthy lifestyle promotes physical and mental fitness within the healthy population.

The present investigation shows that greater arterial stiffness is significantly associated with higher PLI values of the resting-state brain in the $\alpha 2$ band in men and $\beta$ band in women. During task performance, higher spectral power in the $\alpha 2$ band is associated with attention and working memory, ${ }^{40}$ while the $\beta$ band is involved in learning. ${ }^{41}{ }^{42}$ However, the resting state shows a possibly reverse association between connectivity and cognitive functioning, at least in healthy participants or mildly impaired (prodromal) patients; several studies have shown associations between mild cognitive impairments and increased levels of synchronisation in the $\alpha$ and $\beta$ frequencies at rest. ${ }^{43}$ However, in patients with Alzheimer's disease, lower MMSE scores are also 
Figure 1 Significant

sensor-specific associations between PLI and YEM. (A) A

t-map of significant associations

in the $\alpha 2$ band in men. Note:

warm colours refer to positive associations, while cool colours indicate negative associations.

(B) A t-map of significant

associations in the $\beta$ band in women. Note: warm colours refer to positive associations, while cool colours indicate negative associations.
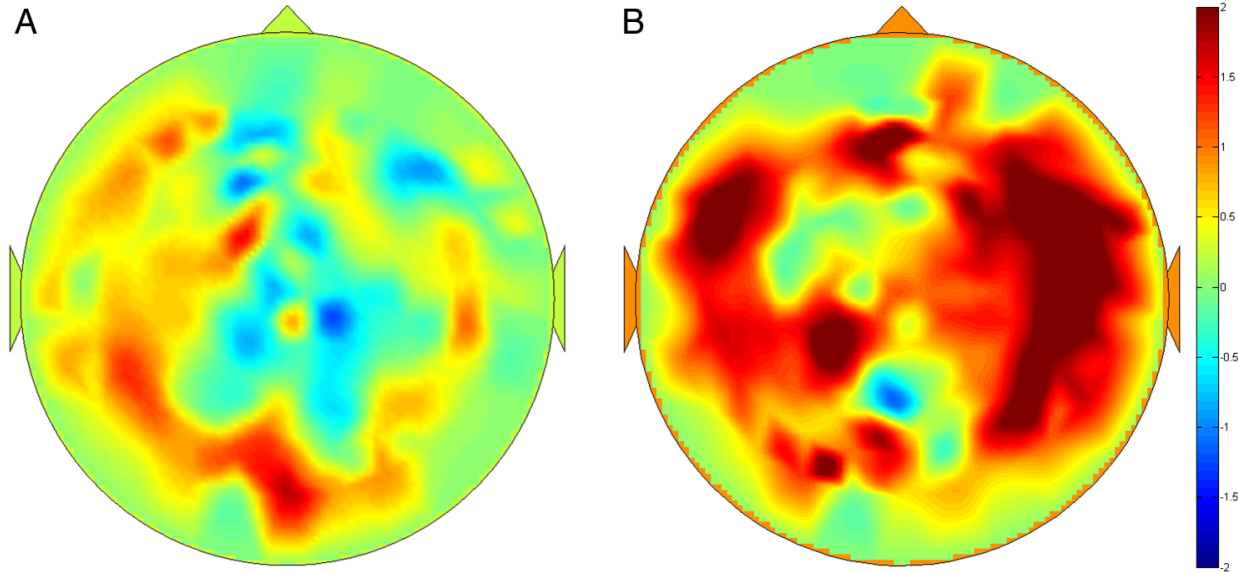

characterised by decreased synchronisation in these frequency bands. ${ }^{45}$

The counterintuitive research findings with regard to the positive correlation between connectivity and carotid stiffness deserve further attention. It is hypothesised that greater brain activity is compensatory behaviour. ${ }^{46}{ }^{47}$ Compensation behaviour is observed in older adults, ${ }^{48}$ but an increase in functional connectivity has also been reported in participants with mild cognitive impairment, which is a precursor of Alzheimer's disease. ${ }^{43}$ It is assumed that the network may work harder to compensate for its own declining efficiency and to deal with the failing parts in the brain. However, whether this hypothesis can be fully applied to connectivity of the brain remains unclear, since this hypothesis merely takes the activity of the brain into account, and we investigated resting-state connectivity. Another possible explanation for the increase in connectivity is that the increase in functional connectivity is not merely the effect of compensatory behaviour, but that it is partly pathological. ${ }^{49}$ A recent modelling study showed that when activitydependent degeneration was simulated, the increase in neuronal activity leads to a degeneration, an inverted-U-relationship. It is assumed that the increase in neuronal activity can be explained by neuronal disinhibition, which makes the highly connected nodes

Table 6 Association between cognitive performance (IQ) and functional connectivity in men

\begin{tabular}{lrll}
\hline & \multicolumn{3}{c}{ Cognitive performance (IQ) } \\
\cline { 2 - 4 } Men & $\boldsymbol{\beta}$ & $\mathbf{p}$ Value & $\mathbf{9 5 \%} \mathrm{Cl}$ \\
\hline Dependent variable & & & \\
PLI $\delta$ & 0.001 & 0.989 & -0.001 to 0.192 \\
PLI $\theta$ & 0.061 & 0.528 & -0.001 to 0.251 \\
PLI $\alpha 1$ & -0.120 & 0.211 & -0.310 to 0.069 \\
PLI $\alpha 2$ & -0.022 & 0.817 & -0.213 to 0.168 \\
PLI $\beta$ & -0.008 & 0.934 & -0.199 to 0.183 \\
PLI $\gamma$ & 0.022 & 0.818 & -0.169 to 0.213
\end{tabular}

Note. Standardised regression coefficients $(\beta)$ as obtained from linear regression analyses.

*Data refer to 110 men. (known as hubs) in the brain more vulnerable to Alzheimer's disease and other mild cognitive impairments. ${ }^{49}$ Since no association is found between functional connectivity and cognitive performance in our study sample, it is likely that a disturbance of the organisation of the functional brain network will be noticeable at a later time point if clinical vascular pathology occurs.

In this study, we used MEG to obtain a recording of the resting-state brain activity and to determine the functional connectivity using PLI. MEG makes it possible to measure real-time neural activity with great temporal precision. Therefore, this study gives a good indication of the relation between arterial stiffness and functional connectivity in healthy middle-aged participants at rest. Further, our findings were obtained in a fairly healthy, highly educated and slightly homogeneous population. ${ }^{22}$ As a consequence, our findings might be slightly underestimated. Furthermore, this study indicates that a difference in gender can be observed in the association between vessel wall stiffness and functional connectivity. Since it is known that the brain organisation differs between men and women, it is important to stratify the results by gender. ${ }^{5-53}$

A limitation of this study is the fact that we are not able to support a temporal or causal relation between arterial stiffness, functional connectivity and full-scale

Table 7 Association between cognitive performance (IQ) and functional connectivity in women

\begin{tabular}{lrlr}
\hline & \multicolumn{3}{c}{ Cognitive performance (IQ)* } \\
\cline { 2 - 4 } Women & $\boldsymbol{\beta}$ & p Value & \multicolumn{1}{c}{$95 \% \mathbf{C l}$} \\
\hline Dependent variable & & & \\
PLI $\delta$ & 0.077 & 0.989 & -0.104 to 0.259 \\
PLI $\theta$ & -0.078 & 0.397 & -0.260 to 0.104 \\
PLI $\alpha 1$ & -0.043 & 0.643 & -0.255 to 0.139 \\
PLI $\alpha 2$ & 0.084 & 0.362 & 0.266 to 0.124 \\
PLI $\beta$ & -0.012 & 0.893 & -0.195 to 0.170 \\
PLI $\gamma$ & 0.001 & 0.990 & -0.181 to 0.183
\end{tabular}

Note. Standardised regression coefficients $(\beta)$ as obtained from linear regression analyses.

*Data refer to 120 women. 
intelligence. This limits the ability to examine specific aspects of cognitive function that might be altered. Therefore, it is recommended in future work to examine executive functions, memory, verbal fluency, speed and attention in relation to carotid stiffness in addition to full-scale intelligence. Moreover, further research is needed in the same participants to determine whether the increase in functional connectivity is a result of greater stiffness of the carotid artery and to determine the long-term effects in relation to cognition. In addition, future work should examine at which point in time vessel wall stiffness is responsible for a decrease in specific aspects of cognitive performance.

Furthermore, it is recommended to apply source-space analyses on MEG data. For these analyses, a participant's MRI must be coregistered with the MEG data to provide a detailed topographical view of the (abnormal) brain activity. ${ }^{54}$ Since MRI scans are not available for the participants within the Amsterdam Growth and Health Longitudinal Study, we were not able to apply the source-space technique in order to provide a detailed topographic view of the brain.

This study shows that greater arterial stiffness of the carotid artery is related to higher functional connectivity in the $\alpha 2$ band and with cognitive performance in men. In women, a positive association of arterial stiffness and functional connectivity can be found in the $\beta$ band. Longitudinal research is necessary to determine the predictive value of arterial stiffness in relation to functional connectivity and cognitive performance in order to grasp the underlying mechanisms of this association and to see whether the phenomenon we observed might be explained by compensatory behaviour. Our results indicate that early diagnostics of arterial stiffness may be promising to identify a disturbance in the organisation of the functional network in a relatively healthy and young population.

\section{Author affiliations}

${ }^{1}$ Department of Methodology and Applied Biostatistics, Faculty of Earth and Life Sciences, VU University Amsterdam, Amsterdam, The Netherlands ${ }^{2}$ Department of Anatomy and Neurosciences, VU University Medical Center, Amsterdam, The Netherlands

${ }^{3}$ Department of Radiology, Athinoula A. Martinos Center for Biomedical Imaging, Massachusetts General Hospital, Charlestown, Massachusetts, USA ${ }^{4}$ Department of Clinical Neurophysiology and MEG Center, VU University Medical Center, Amsterdam, The Netherlands

${ }^{5}$ Department of Physics and Medical Technology, VU University Medical Center, Amsterdam, The Netherlands

${ }^{6}$ Department of Epidemiology and Biostatistics, VU University Medical Center, Amsterdam, The Netherlands

Contributors DN, LD, BWvD, MWH, CJS and JWRT conceived and designed the experiments; LD, BWvD and JWRT performed the experiments; DN, LD, BWvD, CJS and JWRT analysed the data; BWvD and CJS contributed reagents/materials/analysis tools; DN, LD, BWvD, CJS, MWH and JWRT wrote the paper.

Funding This work was supported by grants from the Dairy Foundation, the Netherlands Heart Foundation, the Dutch Prevention Fund, Heineken BV, the Ministry of Public Health, Well-being and Sport (VWS), the Scientific Board of Smoking and Health, the VU University and the VU University Medical Centre since the start of the study in 1976.
Competing interests None declared.

\section{Patient consent Obtained.}

Ethics approval Approved by the medical ethical committee of the VU University, Amsterdam, The Netherlands.

Provenance and peer review Not commissioned; externally peer reviewed.

Data sharing statement All available data can be obtained by contacting the corresponding author.

Open Access This is an Open Access article distributed in accordance with the Creative Commons Attribution Non Commercial (CC BY-NC 4.0) license, which permits others to distribute, remix, adapt, build upon this work noncommercially, and license their derivative works on different terms, provided the original work is properly cited and the use is non-commercial. See: http:// creativecommons.org/licenses/by-nc/4.0/

\section{REFERENCES}

1. Laurent S, Cockcroft J, Van Bortel L, et al. Expert consensus document on arterial stiffness: methodological issues and clinical applications. Eur Heart J 2006;27:2588-605.

2. Mattace-Raso FU, van der Cammen TJ, Hofman A, et al. Arterial stiffness and risk of coronary heart disease and stroke: the Rotterdam Study. Circulation 2006;113:657-63.

3. Singer J, Trollor JN, Baune BT, et al. Arterial stiffness, the brain and cognition: a systematic review. Ageing Res Rev 2014;15:16-27.

4. Hanon $\mathrm{O}$, Haulon $\mathrm{S}$, Lenoir $\mathrm{H}$, et al. Relationship between arterial stiffness and cognitive function in elderly subjects with complaints of memory loss. Stroke 2005;36:2193-7.

5. Pase MP, Pipingas A, Kras M, et al. Healthy middle-aged individuals are vulnerable to cognitive deficits as a result of increased arterial stiffness. J Hypertens 2010;28:1724-9.

6. Poels MM, van Oijen M, Mattace-Raso FU, et al. Arterial stiffness, cognitive decline, and risk of dementia: the Rotterdam study. Stroke 2007;38:888-92.

7. Scuteri A, Brancati AM, Gianni W, et al. Arterial stiffness is an independent risk factor for cognitive impairment in the elderly: a pilot study. J Hypertens 2005;23:1211-16.

8. Scuteri A, Tesauro M, Appolloni S, et al. Arterial stiffness as an independent predictor of longitudinal changes in cognitive function in the older individual. J Hypertens 2007;25:1035-40.

9. Shah NS, Vidal JS, Masaki K, et al. Midlife blood pressure, plasma beta-amyloid, and the risk for Alzheimer disease: the Honolulu Asia Aging Study. Hypertension 2012;59:780-6.

10. Rabkin SW. Arterial stiffness: detection and consequences in cognitive impairment and dementia of the elderly. $J$ Alzheimers Dis 2012;32:541-9.

11. Zeki Al Hazzouri A, Yaffe K. Arterial stiffness and cognitive function in the elderly. J Alzheimers Dis 2014;42:503-14.

12. Mitchell GF. Effects of central arterial aging on the structure and function of the peripheral vasculature: implications for end-organ damage. J Appl Physiol 2008;105:1652-60.

13. Mitchell GF, van Buchem MA, Sigurdsson S, et al. Arterial stiffness, pressure and flow pulsatility and brain structure and function: the Age, Gene/Environment Susceptibility-Reykjavik study. Brain 2011;134:3398-407.

14. Tsao CW, Himali JJ, Beiser AS, et al. Association of arterial stiffness with progression of subclinical brain and cognitive disease. Neurology 2016;86:619-26.

15. Varela F, Lachaux JP, Rodriguez E, et al. The brainweb: phase synchronization and large-scale integration. Nat Rev Neurosci 2001;2:229-39.

16. Bar-Yam Y. Dynamics of complex systems. MA: Addison-Wesley Reading, 1997.

17. Nicolis G, Nicolis C. Foundations of complex systems. Eur Rev 2009;17:237-48.

18. Stam CJ, van Straaten EC. The organization of physiological brain networks. Clin Neurophysiol 2012;123:1067-87.

19. Stam CJ, Nolte G, Daffertshofer A. Phase lag index: assessment of functional connectivity from multi channel EEG and MEG with diminished bias from common sources. Hum Brain Mapp 2007;28:1178-93.

20. Douw L, Schoonheim MM, Landi D, et al. Cognition is related to resting-state small-world network topology: an magnetoencephalographic study. Neuroscience 2011;175:169-77.

21. Hawellek DJ, Hipp JF, Lewis CM, et al. Increased functional connectivity indicates the severity of cognitive impairment in multiple sclerosis. Proc Natl Acad Sci USA 2011;108:19066-71. 
22. Wijnstok NJ, Hoekstra T, van Mechelen W, et al. Cohort profile: the Amsterdam Growth and Health Longitudinal Study. Int J Epidemiol 2013;42:422-9.

23. Kemper HC. Amsterdam growth and health longitudinal study (AGAHLS): a 23-year follow-up from teenager to adult about the relationship between lifestyle and health. Karger Medical and Scientific Publishers, 2004

24. van Mechelen W, Twisk JWR, Post GB, et al. Physical activity of young people: the Amsterdam Longitudinal Growth and Health Study. Med Sci Sports Exerc 2000;32:1610-16.

25. Ferreira I, Henry RMA, Twisk JWR, et al. The metabolic syndrome, cardiopulmonary fitness, and subcutaneous trunk fat as independent determinants of arterial stiffness-the Amsterdam growth and health longitudinal study. Arch Intern Med 2005;165:875-82.

26. Schouten F, Twisk JWR, de Boer MR, et al. Increases in central fat mass and decreases in peripheral fat mass are associated with accelerated arterial stiffening in healthy adults: the Amsterdam Growth and Health Longitudinal Study. Am J Clin Nutr 2011;94:40-8.

27. Van Bortel LM, Balkestein EJ, van der Heijden-Spek JJ, et al. Non-invasive assessment of local arterial pulse pressure: comparison of applanation tonometry and echo-tracking. $J$ Hypertens 2001;19:1037-44.

28. Luteijn F, van der Ploeg F. Handleiding Groninger Intelligentie Test (GIT) Swets and Zeitlinger. Lisse, The Netherlands, 1983.

29. Wechsler D. Wechsler Adult Intelligence Scale-Fourth Edition (WAIS-IV), 2014

30. Kooreman A, Luteijn F. Groninger Intelligentie Test GIT: Schriftelijke verkorte vorm. Lisse: Swets \& Zeitlinger, 1987.

31. Fraschini M, Demuru M, Crobe A, et al. The effect of epoch length on estimated EEG functional connectivity and brain network organisation. J Neural Eng 2016;13:036015.

32. Gross J, Baillet S, Barnes GR, et al. Good practice for conducting and reporting MEG research. Neuroimage 2013;65:349-63.

33. Bernaards CM, Twisk JWR, van Mechelen W, et al. Comparison between self-report and a dipstick method (NicCheck $1 \circledR$ ) to assess nicotine intake. Eur Addict Res 2004;10:163-7.

34. Tarumi T, Gonzales MM, Fallow B, et al. Central artery stiffness, neuropsychological function, and cerebral perfusion in sedentary and endurance-trained middle-aged adults. J Hypertens 2013;31:2400-9.

35. Yam A, Gross AL, Prindle JJ, et al. Ten-year longitudinal trajectories of older adults' basic and everyday cognitive abilities. Neuropsychology 2014;28:819-28.

36. Pase MP, Himali JJ, Mitchell GF, et al. Association of aortic stiffness with cognition and brain aging in young and middle-aged adults: the Framingham Third Generation Cohort Study. Hypertension 2016;67:513-19.
37. Laurent S, Boutouyrie P, Asmar R, et al. Aortic stiffness is an independent predictor of all-cause and cardiovascular mortality in hypertensive patients. Hypertension 2001;37:1236-41.

38. Ferreira I, Twisk JW, Stehouwer CD, et al. Longitudinal changes in VO2max: associations with carotid IMT and arterial stiffness. Med Sci Sports Exerc 2003;35:1670-8.

39. Douw L, Nieboer D, van Dijk BW, et al. A healthy brain in a healthy body: brain network correlates of physical and mental fitness. PLOS ONE 2014;9:e88202.

40. Stam CJ. Brain dynamics in theta and alpha frequency bands and working memory performance in humans. Neurosci Lett 2000;286:115-18.

41. Kounios J, Fleck Jl, Green DL, et al. The origins of insight in resting-state brain activity. Neuropsychologia 2008;46:281-91.

42. Martin C, Beshel J, Kay LM. An olfacto-hippocampal network is dynamically involved in odor-discrimination learning. J Neurophysiol 2007;98:2196-205.

43. Buldu JM, Bajo R, Maestu F, et al. Reorganization of functional networks in mild cognitive impairment. PLOS ONE 2011;6:e19584.

44. Bajo R, Castellanos NP, Cuesta $P$, et al. Differential patterns of connectivity in progressive mild cognitive impairment. Brain Connect 2012;2:21-4.

45. Stam CJ, Jones BF, Manshanden I, et al. Magnetoencephalographic evaluation of resting-state functional connectivity in Alzheimer's disease. Neuroimage 2006;32:1335-44.

46. Reuter-Lorenz PA, Lustig C. Brain aging: reorganizing discoveries about the aging mind. Curr Opin Neurobiol 2005;15:245-51.

47. Reuter-Lorenz PA, Cappell KA. Neurocognitive aging and the compensation hypothesis. Curr Dir Psycholol Sci 2008;17:177-82.

48. van Dinteren R, Arns M, Jongsma ML, et al. Combined frontal and parietal P300 amplitudes indicate compensated cognitive processing across the lifespan. Front Aging Neurosci 2014;6:294.

49. de Haan W, Mott K, van Straaten EC, et al. Activity dependent degeneration explains hub vulnerability in Alzheimer's disease. PLoS Comput Biol 2012;8:e1002582.

50. Schoonheim MM, Hulst HE, Landi D, et al. Gender-related differences in functional connectivity in multiple sclerosis. Mult Scler 2012;18:164-73.

51. Tomasi D, Volkow ND. Laterality patterns of brain functional connectivity: gender effects. Cereb Cortex 2012;22:1455-62.

52. Gootjes L, Bouma A, Van Strien JW, et al. Attention modulates hemispheric differences in functional connectivity: evidence from MEG recordings. Neuroimage 2006;30:245-53.

53. Schoonheim MM, Geurts JJ, Landi D, et al. Functional connectivity changes in multiple sclerosis patients: a graph analytical study of MEG resting state data. Hum Brain Mapp 2013;34:52-61.

54. Hillebrand A, Barnes GR, Bosboom JL, et al. Frequency-dependent functional connectivity within resting-state networks: an Atlas-based MEG beamformer solution. Neuroimage 2012;59:3909-21. 